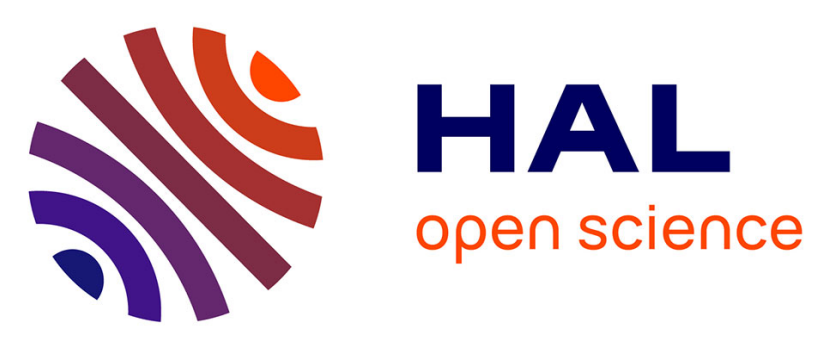

\title{
Numerical investigation on key process parameters affecting blanking of steel sheet by using finite element method
}

Mohamed Lakdhar Sahli, Xavier Roizard, Guillaume Colas, Mohamed Assoul, Pierre-Henri Cornuault

\section{To cite this version:}

Mohamed Lakdhar Sahli, Xavier Roizard, Guillaume Colas, Mohamed Assoul, Pierre-Henri Cornuault. Numerical investigation on key process parameters affecting blanking of steel sheet by using finite element method. International Conference on Material Engineering and Manufacturing, Apr 2020, Tokyo, Japan. hal-02993953

\section{HAL Id: hal-02993953 https://hal.science/hal-02993953}

Submitted on 7 Nov 2020

HAL is a multi-disciplinary open access archive for the deposit and dissemination of scientific research documents, whether they are published or not. The documents may come from teaching and research institutions in France or abroad, or from public or private research centers.
L'archive ouverte pluridisciplinaire HAL, est destinée au dépôt et à la diffusion de documents scientifiques de niveau recherche, publiés ou non, émanant des établissements d'enseignement et de recherche français ou étrangers, des laboratoires publics ou privés. 


\title{
Numerical investigation on key process parameters affecting blanking of steel sheet by using finite element method
}

\author{
M. Sahli ${ }^{1, a}$, X. Roizard ${ }^{1, b}$ G. Colas ${ }^{1, c}$, M. Assoul ${ }^{1, d}$ and P-H. Cornuault ${ }^{1, e}$ \\ ${ }^{1}$ Femto-ST Institute, Applied Mechanics Department, UMR 6174 CNRS, ENSMM, 25030 Besancon \\ cedex, France \\ a mohamed.sahli@femto-st.fr, bxavier.roizard@univ-fcomte.fr, \\ 'guillaume.colas@femto-st.fr, ${ }^{d}$ massoul@univ-fcomte.fr, ${ }^{\mathrm{e}}$ pierre-henri.cornuault@ens2m.fr
}

Keywords: Metal blanking process, simulation, steel sheet, Finite element model.

\begin{abstract}
The cutting surface obtained through the blanking process is often characterized by localized plastic deformations followed by crack propagation and ductile failure. The resulting blanked edge is essentially characterized by known areas such as shear zone, fracture zone and also sometimes burr. Their formation depends essentially on various process parameters and cutting material such as punch/die set, punch speed and temperature. The present study was carried out in order to investigate the possibilities for improving the quality of the cut-surface of high-alloy thick sheet steel. It was focused on modeling and analyzing blanking process of steel sheet using finite element method (FEM). The numerical results of the validation simulations were in agreement with the experimental results, thus validating the model parameters used. The model was developed in order to study the effects of process parameters on the blanking of mechanical steel parts, with particular attention to the study of punch-die gap influence.
\end{abstract}

\section{Introduction}

Blanking is one of the most important processes in the sheet metal forming industry and has umpteen parameters that ensure the required blank quality [1-3]. In this process, the production of metal parts has a major disadvantage which is generally, subsequent deburring is required. This deburring operation is necessary and unfortunately leads to an increase in processing time and labor costs. If the burr formation can be removed by appropriate adjustments to the blanking parameters, there may be a decrease in the final finishing processes and hence a cost [4]. The general objective is to improve the surface quality of blanked parts so that it does not need to be reworked. The main working of blanking process seems quite simple. Initially, a sheet metal strip is placed between the moving punch of predetermined male shape and a fixed die having the appropriate female shape. Then, with the downward movement, the punch cross into the sheet metal while shearing the workpiece into that predetermined shape (see Fig.1a). In blanking process, the blank surface features is usually characterized by localized plastic deformations followed by crack propagation and ductile failure (see Fig.1b). The resulting cut edge is characterized by areas known as rollover, shear zone, fracture zone and also burr. Their formation depends essentially on various parameters of the blanking process, such as the punch-die clearance punch-die radius, punch speed, and temperature [4,5].

In the blanking process, some factors such as the punch-die clearance, the tool geometry and the mechanical properties of the materials influence the quality of the cross section and the dimension precision. Application of FEM in simulation of metal forming processes, also blanking, enables analysis of subsequent stages of the process and prediction of the results of the assumed process parameters, and limitation of costly experiments [5-8]. Several numerical studies were conducted to understand the effect of process parameters on the geometry of the blanked edge including burr, fracture zone, shear surface and rollover. Faura et al (1998), tried to determine optimum clearance by presenting crack propagation angles throughout the sheared edge [7]. Fang et al. (2002) examined the forming quality of the blanking process and concluded substantial effect of punch/die clearance on the shape of the blanked edge [8]. The aim of this paper is to predict the shear stress and plastic strain 
distribution in shearing zone during blanking versus punch-die clearance $(\mathrm{J})$ and their effect on the cut edge quality.

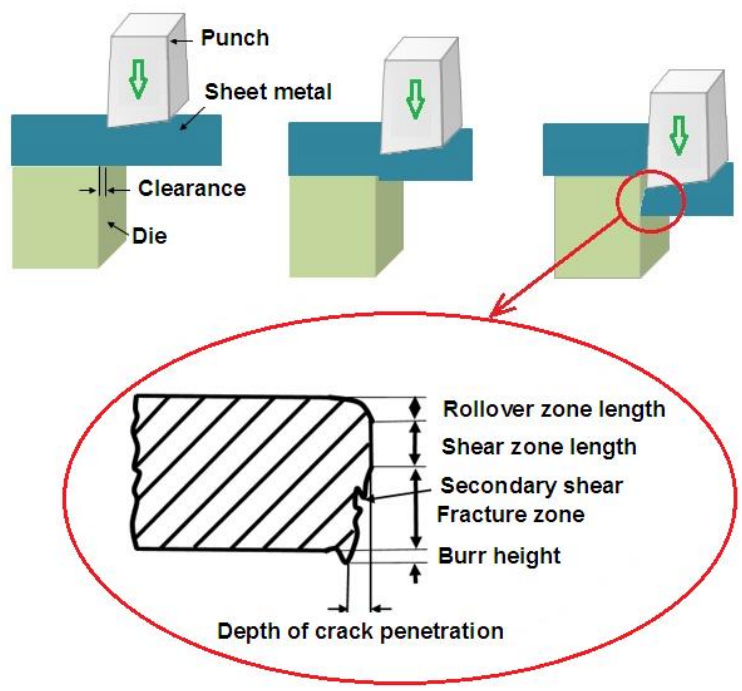

Figure 1. (a) Schematic demonstration of blanking process and (b) description of the shear zone characteristics of the cross section.

\section{Finite Element Model}

Finite element analyser Lsdyna/Explicit were used for the numerical simulation of the finite element model. The punch, lower die and blank holder were considered as rigid bodies and assumed to be non-deformable while the sheet blanking was supposed to be deformable isotropic elasto-plastic material of $4.6 \mathrm{~mm}$ thickness. The exponential hardening law of sheet blanking was identified using tensile tests. Poisson's ratio was 0.3 and Young's modulus was $210 \mathrm{GPa}$ for all materials. The numerical simulations were carried out for three values of punching clearance (clearance/sheet thickness): $5 \%, 10 \%, 15 \%$. The coulomb friction values fitting equal to 0.1 was used in all contacts.

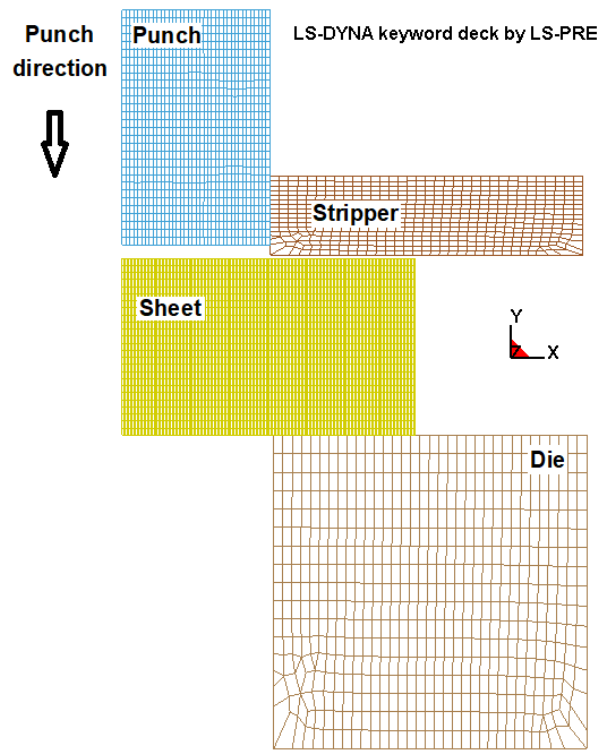

Figure 2. Finite element model of the blanking process and the meshes of the workpiece.

The blanking workpiece was meshed with PLANE183 elements with reduced integration. The total number of elements in the workpiece was about 11172 elements with 25 elements through the sheet thickness. Lagrangian-Eulerian (ALE) adaptive meshing technique in Lsdyna/Explicit was employed to avoid element distortion in the large plastic deformation of necking localization in the 
in-situ tensile tests. The displacement was implemented on the punch and fixed constraint was imposed at the bottom of the die. The axisymmetric view of the designed tool and its components were given in Fig.2.

\section{Material Model and Experimental Parameters}

Blanking Materials. The parts were cut in a sheet made of $16 \mathrm{MnCr} 5$ with a thickness of $4.6 \mathrm{~mm}$, was a commonly used, raw material quality in blanking process. Table 1 shows the chemical composition. To obtain the hardening parameters, tensile tests were conducted using specimens designed according to standards. The tensile test was performed using a servo-electric Instron machine with a maximum load capacity of $100 \mathrm{kN}$, an accuracy of the load cell of $0.2 \%$ with a resolution of $0.01 \mathrm{~N}$ and an accuracy of the displacement cell of $0.06 \%$ with a resolution of $0.001 \mathrm{~mm}$. Tensile test setup with online strain measurement unit was shown in Fig.3.

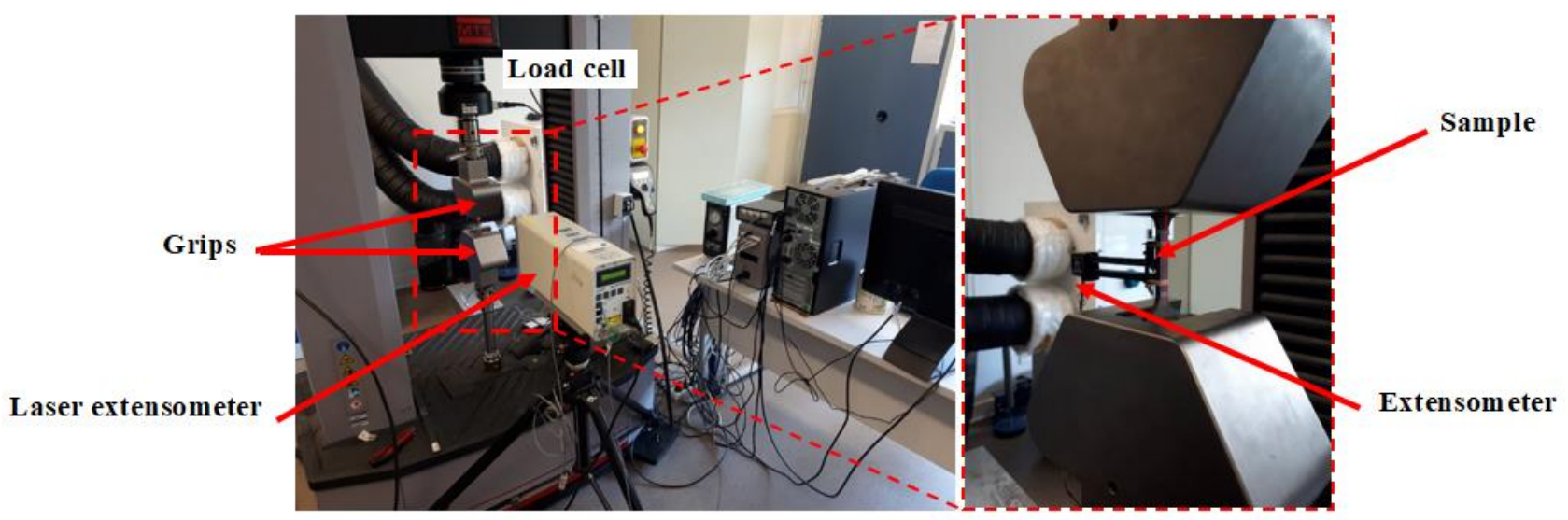

Figure 3. Experimental setup for tensile testing using servo-electric Instron test.

Table 1. Chemical composition (average), [\%].

\begin{tabular}{cccccc}
$\mathbf{C}$ & $\mathbf{S i}$ & $\mathbf{M n}$ & $\mathbf{P}$ & $\mathbf{S}$ & $\mathbf{C r}$ \\
\hline $0.14-0.19$ & 0.40 & $1.00-1.3$ & 0.035 & 0.035 & $0.80-1.1$ \\
& & 0 & & & 0
\end{tabular}

Flat tensile specimens were cuted in such a manner that specimen loading axis lies in the rolling of the sheet or in perpendicular direction. A constant strain rate of $1 \mathrm{~mm} / \mathrm{s}$ was used for conducting the tensile test. All tests were continued until fracture of the sample.

The tensile properties of steel sheet were investigated by applying tensile tests to the flat sample with standard geometry according to DIN50114. The stress-strain curves of samples with different loading angles, i.e. the angle of the loading directions with respect to the rolling and transverse direction, were shown in Fig.4. The rolling direction develops a preferred crystallographic orientation in the microstructure that results in a higher strength (Fig.4). In this regard mechanical properties tend to be lower in the transverse direction which is perpendicular. All of these experimental data was implemented in simulation codes to describe the constitutive model of the steel sheet. 


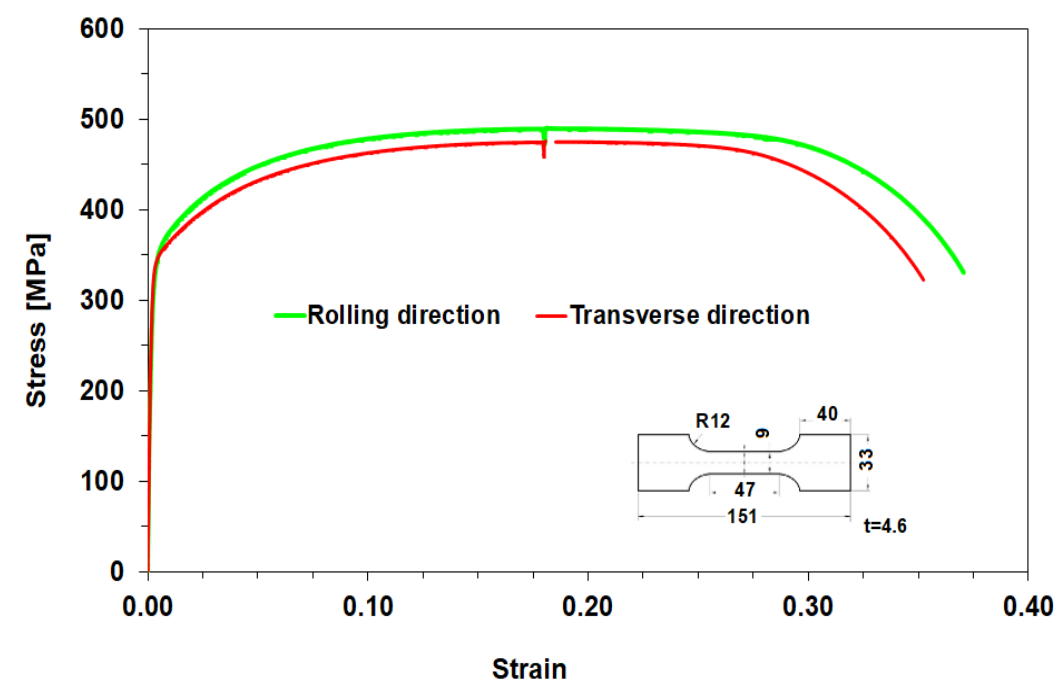

Figure 4. Stress-strain relationship of $16 \mathrm{MnCr} 5$.

Blanking Test Description. The blanking tool consists of a moving upper part and a fixed lower part. The upper part was instrumented with a displacement, force and thermals sensors, placed close to the punch. The instrumented tool was designed to cut a mechanical component from a $4.6 \mathrm{~mm}$ thick sheet metal band. The blanking tests were performed on a mechanical press with a speed of 30 strokes/min. For this part, a cycle time of $1.5 \mathrm{~s}$ was used, whereby the actual cut requires approximately $0.4 \mathrm{~s}$. The stroke of the punch $(\varnothing)$ was set so as to obtain a penetration depth of $5.8 \mathrm{~mm}$. The clearance punch/stripper and punch/die were $0.01 \mathrm{~mm}$ and 0.1 to 0.3 , respectively. Fig. 5 presents macro photograph of sections of a cut-out zone made with the use of a cylindrical punch showing the different edge areas: rollover, sheared, fracture and burr zones. The magnification of the zone near the shear cut edge illustrates the degree of deformation of the microstructure. The depth of the shear affected zone was approximately $3.6 \pm 0.2 \mathrm{~mm}$, which corresponds to more than one half of the sheet metal thickness.

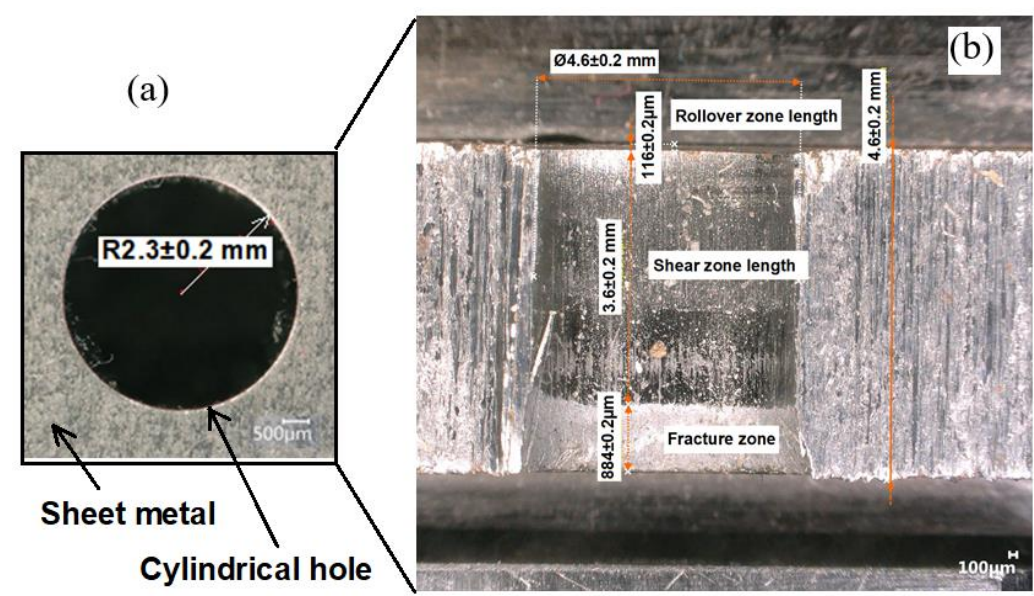

Figure 5. (a) Blanking process of sheet metal: (a) sheet metal with cylindrical hole, and (b) cross-sections of sample.

Numerical Results and Discussion. A comparison of shear stress distribution between blanking with reduced clearance of $0.01 \mathrm{~mm}$ (case 1) and blanking with $10 \%$ or $15 \%$ clearance (cases $2 \& 3$ ) was shown in Fig.6. The decrease in clearance limits bending moment acting on the blank due to the lateral displacement between cutting edges. It is also showed the essential influence of clearance on stress values in the shearing zone and consequently on the cut-surface shape. 

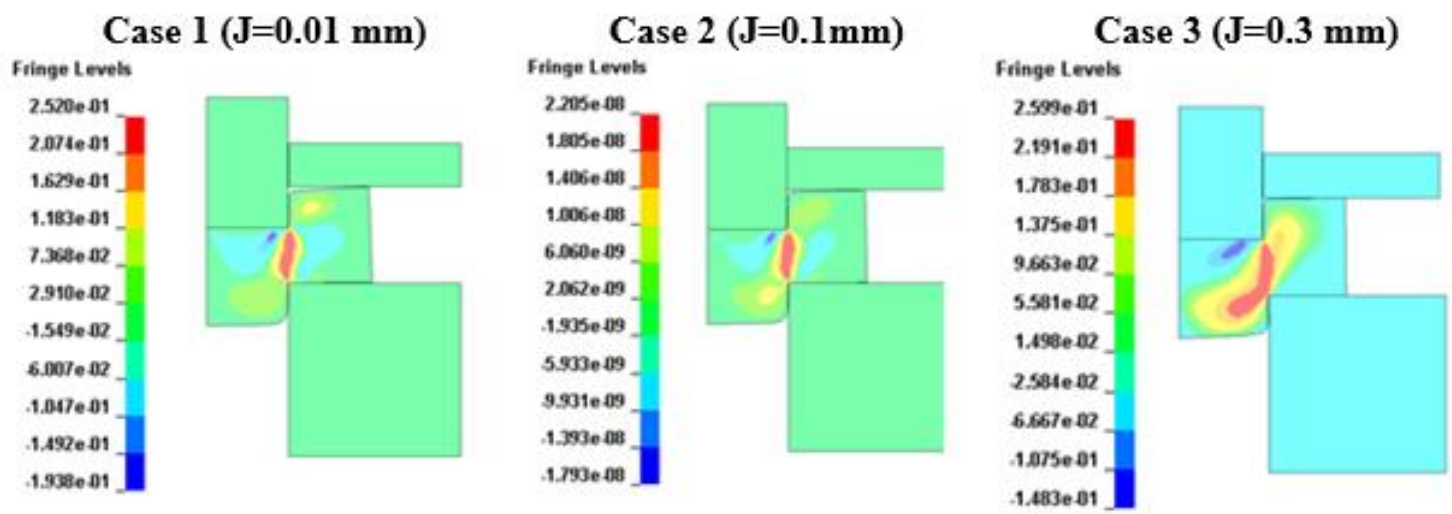

Figure 6. Shear stress distribution in shearing zone (at 73ms).

The plastic strains distribution evolution obtained through FEM in shearing zone during blanking process (case 2) with sheet compression is shown in the Fig.7. During blanking plasticized zones spreading from the cutting edges of the die and punch, where the plastic deformations initiate, join earlier. Clearance reduction leads to the delay of fracture initiation. All these give smoother cut-surface. As a result, a high quality cut-surface is produced. It should be noted, however, that there is likely to be a minimum clearance limit below which cutting conditions may deteriorate [9].

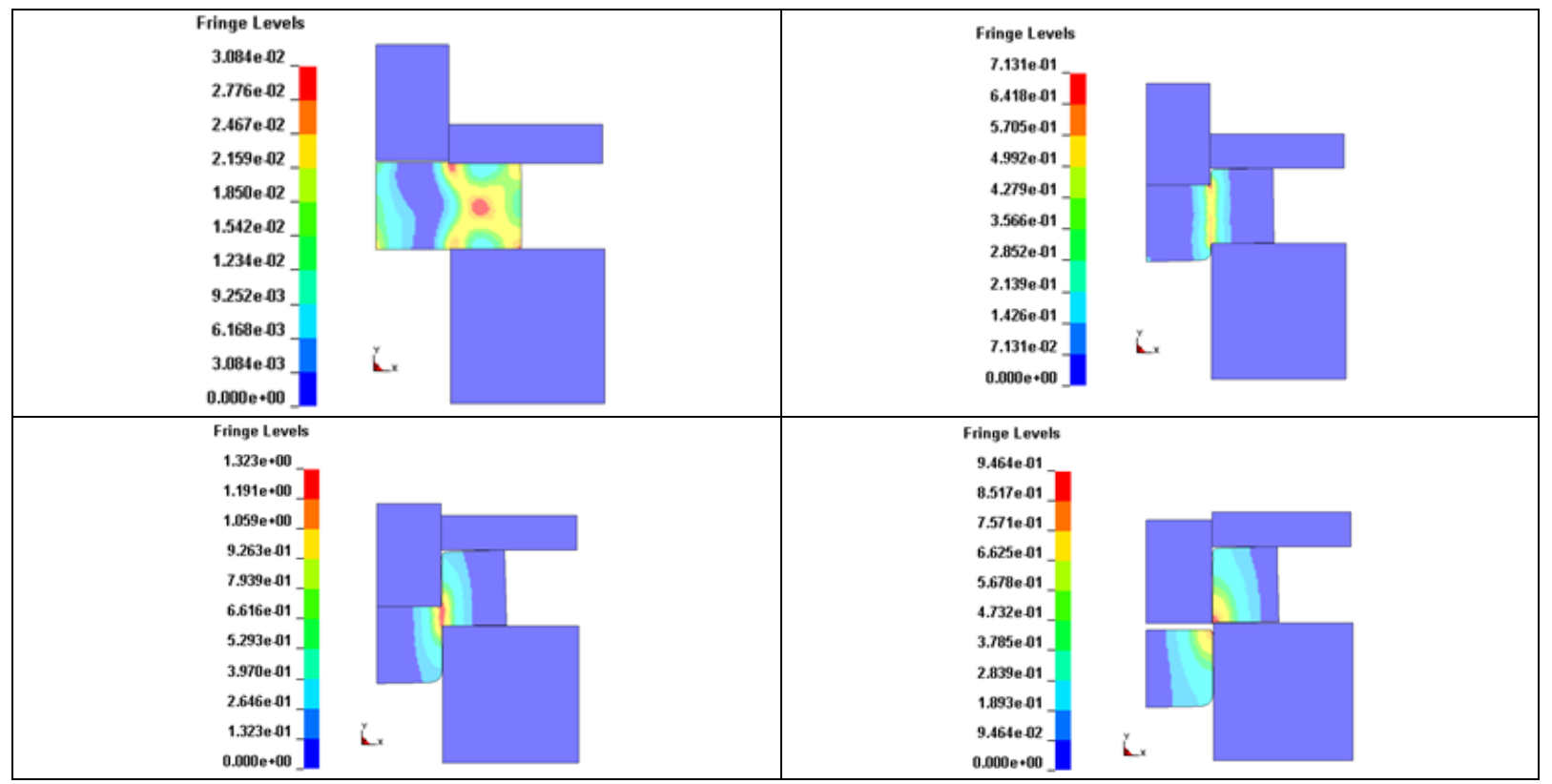

Figure 7. Plastic strain distribution vs. times during blanking process (case 2).

Experimental Validation. Fig.8 shows the real punch displacement evolution during blanking process (green curve). We can notice that the proposed model (red curve) overestimates a little punch displacement values and more particularly at the end of sheet cutting. Indeed, the simulation does not take into account the different stiffness of blanking tool, a deformable behavior of punch and the punch temperature as well as lubrication. However, we will consider the gap between experimental and numerical results as reasonable in a first approach. 


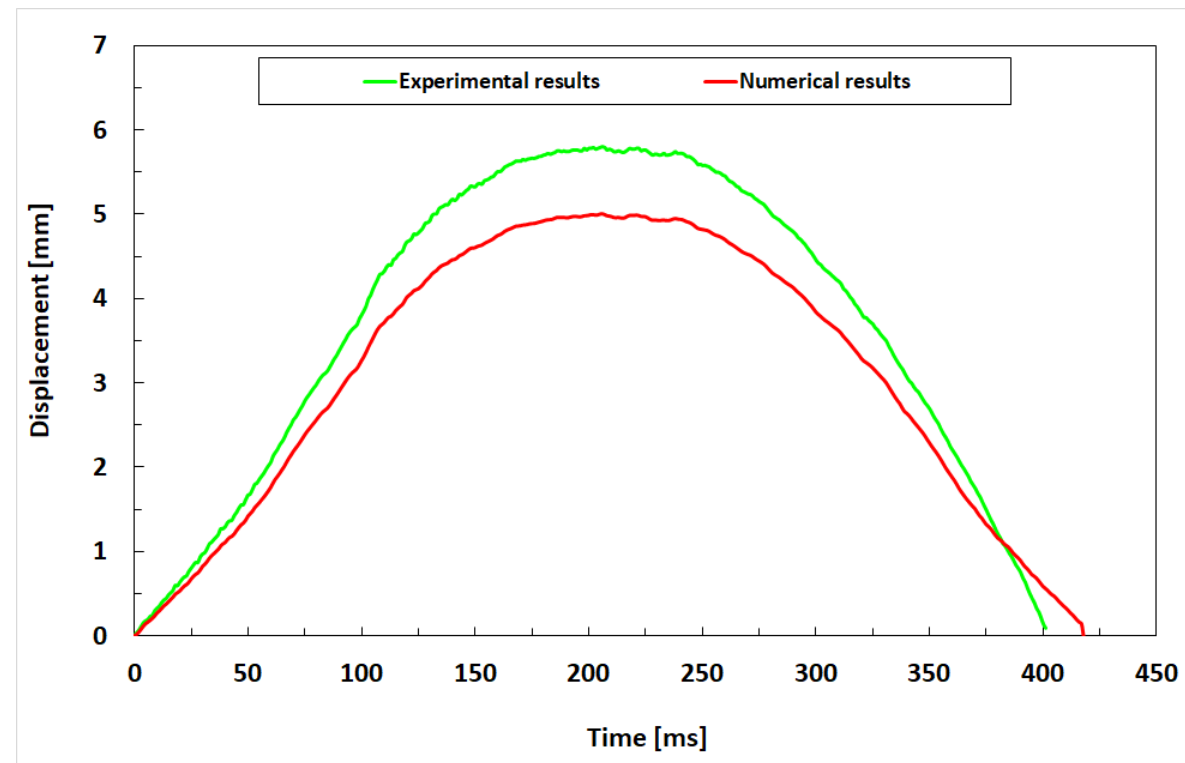

Figure 8. Punch displacement vs. time during blanking process compared to experiment result.

\section{Conclusions}

This study focuses on numerical investigation of the blanking process. Based on the results obtained, the following conclusions can be drawn:

- During of numerical simulations of the blanking process an elongation in shear surface and a simultaneous reduction in fracture zone versus clearance punch/die was observed.

- The blanking course and cut-surface shape quality dependent of clearance punch/die. Generally, clearance reduction leads to the delay of fracture initiation, and consequently, all these give smoother cut-surface.

- Results from the numerical model agrees well with the experimentally obtained results, considering both predicted punch displacement behavior as well as the geometry of the punched edge profiles.

\section{References}

[1] Y. Liu, L. Hua, H. Mao, W. Feng: Procedia Eng. Vol. 81 (2014), p. 1108-1113

[2] M.L. Penalva, M. Arizmendi, F. Diaz, J. Fernandez, Z. Katz: CIRP Ann. Manuf. Technol. Vol. 51 (2002), p. 57-60

[3] G. Monteil, F. Gréban, X. Roizard: Wear Vol. 265 (2008), p. 626-633

[4] S.K. Maiti, A.A. Ambekar, U.P. Singh, P.P. Date, K. Narasimhan: J. Mater. Process. Technol. Vol. 102 (2000), p 249-256

[5] N. Mole, B. Stok: Int. J. Mater. Form., Vol. 1 (2009), p. 551-554

[6] E. Falconnet, J. Chambert, H. Makich, G. Monteil: Wear Vol. 338 (2015), p. 144-154

[7] F. Faura, A. Garcia and M. Estrems: J. Mater. Process. Tech. Vol. 80-81 (1998) p. 121-125

[8] G. Fang, P. Zeng, L. Lou: J. Mater. Technol. Vol. 122 (2002), p. 249-254

[9] S. Subramonian, T. Altan, B. Ciocirlan, C. Campbell: Int. J. Machine Tools and Manuf. Vol. 75 (2013), p 63-71 